\title{
PROFEMINIS DAN KONTRAFEMINIS TOKOH HANAH DALAM GERPEN TELAPAK KAKI YANG MENYIMPAN SURGA KARYA NI KOMANG ARIANI
}

\author{
SITI ELY IRMAWATI, EVI CHAMALAH, DAN TURAHMAT \\ Prodi PBSI, FKIP Universitas Islam Sultan Agung \\ elyirmawati94@gmail.com, chamalah@unissula.ac.id, lintangsastra@unissula.ac.id
}

Pertama Diterima: 01 Juni 2017 Bukti Akhir Diterima: 06 Juni 2017

\begin{abstract}
ABSTRAK
Cerpen yang berlatar belakang lika-liku kehidupan rumah tangga Hanah, memperlihatkan kepatuhan tokoh Hanah yang selalu berada dalam kekuasaan lakilaki yaitu pada suaminya. Penelitian ini secara umum bertujuan untuk memperoleh deskripsi tentang profeminis dan kontrafeminis tohoh Hanah dalam cerpen Telapak Kaki yang Menyimpan Surga karya Ni Komang Ariani pada koran Jawa Pos Edisi 18 September 2016. Metode yang digunakan dalam penelitian ini yaitu metode deskriptif kualitatif. Selanjutnya pendekatan feminisme dilakukan untuk mengetahui profeminis dan kontra feminis tokoh Hanah sebagai istri maupun sebagai seorang wanita pada umumnya. Hasil penelitian ini menunjukkan bahwa tokoh Hanah termasuk golongan kontrafeminis karena ia lebih mematuhi apapun yang dikatakan suaminya ketimbang ia beraktivitas diluar rumah. Tapi tak dipungkiri juga bahwa sosok Hanah mempunyai keinginan untuk sekolah dan melakukan aktivitas di luar rumah karena permintaan suaminya untuk berpoligami. Kata kunci: Profeminis, Kontrafeminis, Tokoh Hanah, Cerpen
\end{abstract}

\begin{abstract}
The background of short story is about intricacies of Hanah's household life, which shows the character of Hanah's obidience that always be in the authorization of man, that is her husband. This study in general aimed to obtain the description about prosfeminism and consfeminism of Hanah's figure in the short story Telapak Kaki yang Menyimpan Surgawhich was written by Ni Komang Ariani in the Jawa Pos newspaper whichis published on 18 September 2016. The method used in this study was descriptive qualitative methods. Furthemore the approach of feminism was done to knowing about prosfeminism and consfeminism of Hanah as a wife or women in general. The results of research showed that Hanah belonged consfeminism because she was more obeyed anything her husband's told then doing activity outside the house. But,actually Hanah wished to go to school and do activities outside the house because her husband demanded to commit polygamy.
\end{abstract}

Keyword : Profeminism, Consfeminism, Tokoh Hana, Cerpen

\section{PENDAHULUAN}

Kaum wanita selama ini hanya dipandang sebagai makhluk sosial yang posisinya dibawah kaum laki-laki. Dalam hal berkarir wanita kurang mendapat kesempatan untuk mengembangkan bakat yang dimilikinya. Kurangnya pengakuan terhadap kemampuan yang 
dimiliki wanita membuat kaum wanita merasa dipandang sebelah mata. Seperti halnya wanita dalam masyarakat Jawa yang masih dipandang sebelah mata yang erat kaitanya dengan istilah masak, macak, manak yang artinya wanita itu harus pandai memasak, pandai berdandan, dan pandai memberikan keturunan. Selain itu wanita yang sudah bersuami harus patuh terhadap suaminya, meskipun seorang istri juga punya hak untuk menyuarakan isi hatinya (Nugraheni, Imas Anggita 2015). Dari banyaknya tuntutan dan kurangnya pengakuan terhadap bakat yag dimiliki wanita maka munculah persoalan dalam diri wanita itu sendiri, yang sering disebut dengan feminisme karena wanita juga ingin mengembangkan bakat yang dimilikinya.

Dalam ilmu sastra, kajian mengenai perempuan dikenal sebagai kritik sastra feminis. Kritik sastra feminis dilakukan untuk menunjukkan citra perempuan dalam karya para penulis laki-laki yang menampilkan perempuan sebagai makhluk dengan berbagai cara ditekan, disalahtafsirkan, serta disepelekan oleh tradisi patriarki yang dominan.

Feminisme digolongkan menjadi dua bagian, yaitu tokoh profeminis dan tokoh kontrafeminis (Djajanegara 2000:2). Dalam hal ini tokoh profeminis menggambarkan tokoh yang setuju dan memperjuangkan ide feminis, sedangkan kontafeminis menggambarkan tokoh yang tidak setuju dan tidak memperjuangkan, bahkan menentang feminisme. Yang termasuk golongan profeminis adalah wanita-wanita yang memiliki kemauan mendorong dirinya untuk maju, melakukan kegiatan di luar rumah tangga, mandiri atau tidak bergantung pada laki-laki baik dari segi psikis maupun ekonomi (Djajanegara 2000:5).

Sementara itu golongan kontrafeminis adalah wanita yang memiliki sikap pasif, menyerah, dan tidak mandiri. Djajanegara (2000:52) juga disebutkan wanita yang merasa puas dan bahagia dengan hanya semata-mata mengurus keluarga dan rumah tangga juga termasuk kategori kontrafeminis. Wanita demikian membiarkan dirinya tidak saja bergantung pada suami dan kemudian pada anak-anaknya, melainkan juga tidak sanggup mengembangkan dirinya menjadi orang yang mandiri secara jasmani maupun secara intelektual. Gambaran profeminis dan kontrafeminis yang diwakilkan oleh tokoh perempuan dapat dilihat dalam cerpen Telapak Kaki yang Menyimpan Surga karya Ni Komang Ariani pada koran Jawa Pos Edisi 18 September 2016.

Cerpen Telapak Kaki yang Menyimpan Surga menceritakan seorang perempuan bernama Hanah yang ingin memberikan keturunan untuk suaminya agar dia bisa melihat surga yang dimilikinya. Surga yang selalu dielu-elukan anaknya kelak akan menjadi kebanggan tersendiri untuk suaminya dan juga untuk rumah tangganya. Sekian tahun mengarungi rumah tangga bersama suaminya, Hanah adalah sosok istri yang berbakti pada 
sang suami, apapun yang dikatakan suaminya ia akan mematuhinya. Hannah tak pernah melawan dan selalu tersenyum meskipun perkataan sang suami begitu menyinggung hatinya, sampai pada akhirnya ia juga harus tetap tersenyum, meski menelan pil pahit saat sang suami mengatakan bahwa ia akan menikahi perempuan lain agar bisa mendapatkan keturunan tanpa menceraikan Hanah. Hanah ingin menolak tapi tak punya kuasa untuk itu, akhirnya ia mengizinkan suaminya berpoligami tapi dengan syarat ia ingin sekolah lagi dan melakukan aktivitas diluar rumah dan suaminyapun mengizinkannya. Dari sinopsis tersebut terlihat bentuk profeminis dan kontrafeminis pada cerpen Telapak Kaki yang Menyimpan Surga karya Ni Komang Ariani pada koran Jawa Pos Edisi 18 September 2016. Alasan itulah yang membuat peneliti meneliti kajian feminisme pada cerpen tersebut.

Adapun rumusan masalah yang akan diteliti adalah bagaimana bentuk profeminis dan kontafemenis dalam cerpen Telapak Kaki yang Menyimpan Surga karya Ni Komang Ariani pada koran Jawa Pos Edisi 18 September 2016? Tujuan penelitian ini adalah untuk mengetahui bentuk profeminis dan kontafemenis dalam cerpen Telapak Kaki yang Menyimpan Surga karya Ni Komang Ariani pada koran Jawa Pos Edisi 18 September 2016. Adapun manfaat penelitian ini yaitu secara teoretis pembaca mendapatkan gambaran mengenai feminisme pada sebuah karya sastra khususnya cerpen. Secara praktik dapat digunakan sebagai pembelajaran buat kaum laki-laki dan juga perempuan bahwa tidak selamanya kaum perempuan dikesampingkan atau dinomorduakan. Emansipasi wanita adalah bentuk nyata dari kesetaraan gender di zaman modern ini.

Berdasarkan hasil pengamatan, peneliti belum pernah menemukan penelitian mengenai pengkajian profeminis dan kontrafeminis dalam cerpen Telapak Kaki yang Menyimpan Surga karya Ni Komang Ariani pada koran Jawa Pos Edisi 18 September 2016. Namun, penelitian mengenai perempuan sudah pernah diteliti oleh Adji (2009), Uli (2011), Danial (2012), Asmalasari (2013), Ismawati (2013), Syahfitri (2013), Qomariyah (2013), Juliah (2015), Solichah (2015), Gora (2015), dan Apriliya (2016).

\section{METODE PENELITIAN}

Jenis penelitian yang digunakan untuk mengkaji cerpen Telapak Kaki yang Menyimpan Surga karya Ni Komang Ariani pada koran Jawa Pos Edisi 18 September 2016 adalah metode kualitatif. Metode kualitatif adalah penelitian yang bermaksud untuk memahami fenomena apa yang dialami oleh subjek penelitian misalnya perilaku, persepsi, motivasi, dan lain-lain dan dengan cara deskripsi dalam bentuk kata-kata dan bahasa, pada suatu konteks khusus yang alamiah dan dengan memanfaatkan metode alamiah (Moleong 
2008: 6). Data dapat diperoleh melalui naskah dan catatan. Objek yang dikaji dalam penelitian ini adalah kajian feminisme dalam cerpen Telapak Kaki yang Menyimpan Surga karya Ni Komang Ariani pada koran Jawa Pos Edisi 18 September 2016.

Pendekatan yang digunakan dalam penelitian ini adalah pendekatan kritik sastra feminisme. Pendekatan feminis digunakan untuk membantu membongkar bentuk ketidakadilan gender yang dialami oleh tokoh perempuan yang terdapat dalam cerpen Telapak Kaki yang Menyimpan Surga karya Ni Komang Ariani pada koran Jawa Pos Edisi 18 September 2016. Kritik sastra feminis merupakan kesadaran membaca sebagai wanita, yakni kesadaran pembaca bahwa ada perbedaan penting dalam jenis kelamin pada makna dan perebutan makna karya sastra (Culler dalam Sugihastuti 2010:7). Artinya membaca dengan kesadaran bahwa ada jenis kelamin yang banyak berhubungan dengan budaya, sastra, dan kehidupan serta membongkar praduga dan ideologi kekuasaan lakilaki yang andosentris dan patriarki karena karya sastra Pendekatan Pada penelitian yang penulis lakukan, objek kajian berupa teks sastra. Teks sastra dideskripsikan, dianalisis, dan ditafsirkan sehingga menghasilkan data deskriptif tertulis.

Sumber data yang digunakan dalam penelitian ini adalah data kepustakaan yaitu berupa buku, transkrip, majalah, dan lain-lain. Hal ini sejalan dengan perincian sebagai berikut. Sumber data primer penelitian ini adalah cerpen Telapak Kaki yang Menyimpan Surga karya Ni Komang Ariani pada koran Jawa Pos Edisi 18 September 2016. Sumber data sekunder merupakan sumber data kedua. Sumber data sekunder dalam penelitian ini yaitu data-data yang bersumber dari buku-buku acuan yang berhubungan dengan permasalahan yang menjadi objek penelitian.

Data karya sastra berupa kutipan kalimat yang menunjukkan feminisme yang diduga berisi kalimat-kalimat bergaya bahasa sarkasme. Data penelitian ini berasal dari cerpen Telapak Kaki yang Menyimpan Surga karya Ni Komang Ariani pada koran Jawa Pos Edisi 18 September 2016.

Teknik pengumpulan data pada penelitian ini adalah studi pustaka, yaitu menelaah isi cerpen Telapak Kaki yang Menyimpan Surga karya Ni Komang Ariani pada koran Jawa Pos Edisi 18 September 2016 dengan cara membaca dan mencatat bagian-bagian teks yang memperlihatkan bentuk adanya feminisme. Adapun langkah-langkah yang dilakukan dalam penelitian adalah sebagai berikut. (1) Membaca cerpen Telapak Kaki yang Menyimpan Surga karya Ni Komang Ariani pada koran Jawa Pos Edisi 18 September 2016 secara keseluruhan dari awal sampai akhir secara berulang-ulang supaya memahami isi yang terdapat dalam cerpen tersebut; (2) Mencatat kutipan-kutipan yang diduga mengandung unsur feminisme; (3) 
Menganalisis data sesuai dengan rumusan masalah yaitu bagaimana bentuk feminisme cerpen Telapak Kaki yang Menyimpan Surga karya Ni Komang Ariani pada koran Jawa Pos Edisi 18 September 2016; (4) Membuat simpulan hasil analisis.

Teknik analisis data untuk penelitian ini dilakukan dengan cara pengumpulan data dari penelitian yang sudah ada, menganalisis unsur feminisme dalam cerpen Telapak Kaki yang Menyimpan Surga karya Ni Komang Ariani pada koran Jawa Pos Edisi 18 September 2016, melakukan penelitian.

\section{HASIL PENELITIAN DAN PEMBAHASAN}

Feminisme bisa dikatakan memperjuangkan dua hal yang selama ini tidak dimiliki kaum wanita pada umumnya, yaitu persamaan derajat mereka dengan laki-laki dan otonomi untuk menentukan apa yang baik bagi dirinya. Dengan kata lain, feminisme merupakan gerakan kaum wanita untuk memperoleh otonomi atau kebebasan menentukan dirinya sendiri. Dalam penelitian ini ditemukan profeminis dengan 2 data dan kontrafeminis dengan 4 data seperti pada uraian dibawah ini. Pada analisis kritik sastra feminis ini peneliti menggolongkan menjadi dua yaitu, tokoh profeminis dan tokoh kontrafeminis.

\section{Profeminis Tokoh Hanah dalam cerpen Telapak Kaki yang Menyimpan Surga karya Ni} Komang Ariani pada koran Jawa Pos Edisi 18 September 2016.

Hasil temuan penelitian ini terdapat tokoh profeminis yang memiliki kemauan untuk maju, melakukan kegiatan di luar rumah tangga, mandiri atau tidak bergantung pada laki-laki baik dari segi psikis maupun ekonomi. Tokoh profeminis adalah tokoh-tokoh yang mendukung ide-ide feminis. Sedangkan tokoh kontrafeminis adalah tokoh-tokoh yang memilih hidup tidak mandiri dan di bawah laki-laki. Tokoh yang termasuk dalam profeminis dalam "Telapak Kaki yang Menyimpan Surga” adalah Hanah.

\section{a. Profeminis Prilaku}

Hanah adalah sosok seorang istri yang sangat patuh pada suaminya, meskipun Hanah dimadu oleh suaminya tetapi ia tidak terpuruk dengan keadaanya, melainkan ia lebih memilih untuk sekolah dan menjalankan aktivitas diluar rumah tangganya. Hal ini terbukti dalam kutipan cerpen berikut.

"Boleh saya minta sesuatu darimu?"

“Tentu boleh, Hanah. Mintalah apa saja, karena kau adalah seorang perempuan yang 
mulia."

"Saya ingin sekolah. Boleh, kan?” Dia terkesiap.

"Tentu boleh. Perempuan harus pintar."

Aku menarik napas lega.

"Namun kau harus tahu, kau sekolah tinggi bukan untuk bersaing denganku, apalagi mengungguliku. Kau sekolah tinggi untuk mendidik anak-anak kita kelak menjadi orangorang dewasa yang berkilauan."

“Tentu," jawabku dengan senyum yang merekah. Terngiang pergunjingan dua kawan perempuanku. Membicarakan tentang seorang perempuan menjijikkan yang bersuamikan dua orang laki-laki. Hatiku seperti direndam dalam cairan asam. Segalanya tak penting, ketika ia mengizinkanku bersekolah. Kelahiranku yang sebenarnya baru terjadi setelah aku sekolah. Sebuah permulaan dari hal-hal yang tidak terbayangkan kemudian. *** (Telapak Kaki yang Menyimpan Surga karya Ni Komang Ariani pada koran Jawa Pos Edisi 18 September 2016)

Berdasarkan kutipan diatas dapat disimpulkan bahwa Hanah merupakan tokoh profeminis tampak dari sikapnya yang setuju dengan tindakan suaminya yang ingin menikah lagi. Pada umumnya seorang wanita akan maraha atu meminta cerai pada suaminya disaat sang suami meminta untuk menikah lagi. Tapi tidak dengan Hanah yang memiliki pemikiran bahwa surganya seorang istri berada pada suami. Dalam islampun juga diperbolehkan berpoligami dengan syarat bisa berbagi dengan adil. Dari situlah Hanah mengizinkan dirinya dimadu dengan syarat dirinya diperbolehkan untuk mengenyam bangku pendidikan lagi. Hanah ingin menjadi wanita yang mandiri dan tidak tergantung pada sang suami. Dengan dirinya mengenal dunia luar dan bisa melanjutkan hidup dengan berbagi suami bersama madunya.

\section{b. Profeminis Pemikiran}

Keinginan Hanah menjadi istri yang sempurna untuk suaminya mengharuskan ia menerima segala sesuatu yang diucapkan ataupun yang diinginkan suaminya. Tetapi Hanah juga berani memberikan alasan atau mengungkapkan pikiranya meskipun sang suami tidak menyukai alasannya. Berikut kutipan cerpennya.

Dia tersenyum ragu. "Bagaimana dengan baju-baju yang aku sarankan sebulan yang lalu. Kaти belum menggantinya seperti yang aku minta." Aku tersengat gundah. "Maafkan saya. Belum ada uang untuk membeli model yang seperti itu. Harga-harga sembako naik.” (Telapak Kaki yang Menyimpan Surga karya Ni Komang Ariani pada koran Jawa Pos Edisi 18 September 2016). 
Berdasarkan kutipan tersebut tokoh Hanah memang menjadi istri yang tetap patuh pada suami. Tapi, seorang Hanah punya pemikiran sendiri dan tanpa segan ia ucapkan pada suaminya. Seperti kutipan tersebut, Hanah berani memberikan alasan kenapa dirinya belum mengganti atau membeli baju yang disarankan suaminya dikarenakan belum ada uang sebab harga sembako saat itu sedang naik. Seorang wanita tentunya juga punya hak yang sama dalam mengutarakan pendapat atupun alasan saat sedang berdiskusi.

\section{Kontrafeminis Tokoh Hanah dalam Cerpen Telapak Kaki yang Menyimpan Surga karya Ni Komang Ariani pada koran Jawa Pos Edisi 18 September 2016.}

Selain tokoh profeminis, peneliti juga menemukan tokoh-tokoh kontrafeminis yang bersifat pasif, menyerah, mengurus keluarga dan rumah tangga, tidak mandiri dan bergantung pada suami.

\section{a. Sikap Pasif}

Dalam cerpen tergambar dengan jelas bagaimana kehidupan seorang istri bernama Hanah yang harus takdzim dengan semua ucapan-ucapan suaminya yang menyinggung hatinya.

Sosok Hanah dalam cerpen tersebut menggambarkan bahwa wanita tak punya hak untuk membela diri. Hal ini terbukti dalam kutipan cerpen berikut.

Dia melengos gelisah. “Kamu jangan mulai memberi alasan, dengan menimpakan kesalahan kepadaku. Seolah-seolah aku gagal mencukupi hidupmu.”

Darah deras mengaliri mukanya. Urat-urat di wajahnya menegang. Seperti ada yang menariknya dari keempat penjuru. Hatiku mencelos. Dosa apa lagi yang bakal kubuat sepagi ini. Subuh bahkan belum pergi. Halaman rumah belum disapu, nasi belum ditanak. Pakaianpakaian kotor masih menumpuk. Baru air panas yang terjerang, untuk menyeduh kopinya setengah jam yang lalu.

“Tentu tidak, Mas. Uang bulanan darimu sangat cukup dan berlebih. Sayalah yang tak pandai mengaturnya. Saya perempuan yang teramat bodoh. Maafkan saya.” (Telapak Kaki yang Menyimpan Surga karya Ni Komang Ariani pada koran Jawa Pos Edisi 18 September 2016).

Dari kutipan tersebut menggambarkan bahwa Hanah merupakan tokoh kontrafeminis, dilihat dari sikap Hanah yang tunduk, takut, dan merendahkan dirinya didepan suaminya. Sifat pasif yang dimiliki Hanah membuat suaminya semena-mena terhadapnya. Seorang istri yang tidak mau mengutarakan apa yang menjadi keinginannya dan hanya menerima segala ucapan dan tindakan suami meski itu menyakiti hatinya. Sikap seperti yang terkadang 
semakin membuat wanita dipandang rendah dan lemah oleh laki-laki.

Pada kutipan selanjutnya juga tedapat sikap kontrafeminis dalam diri Hanah yang bersifat pasif.

"Ya sudah. Hari sudah siang. Saya harus berangkat. Jaga rumah baik-baik ya. Jaga juga kehormatan keluarga," pesannya waktu itu. Agak terburu. Sedan tuanya menggerung. Aku lupa kapan tepatnya aku pernah duduk di sebelahnya di mobil itu. Sungguh aku menginginkannya. Seumur-umur mobil yang kunaiki hanya angkot. Tanpa AC dan bau knalpot menyerbu dari segala penjuru.

“Aku memang berjanji untuk mengajakmu jalan-jalan, tapi ingat waktu itu akan tiba pada hari pertama ketika anak kita lahir. Aku akan menjemputmu dari rumah sakit dengan mobil ini. Namun sekarang bukan saatnya untuk bersenang-senang. Kita harus banyak menabung. Bensin mahal kalau dihamburkan untuk jalan-jalan. Jadi mobil ini hanya kugunakan untuk pergi dan pulang kerja. Kau tahu kan bahwa biaya persalinan mahal?" (Telapak Kaki yang Menyimpan Surga karya Ni Komang Ariani pada koran Jawa Pos Edisi 18 September 2016).

Kutipan tersebut menggambarkan kontrafeminis pada diri Hanah, dilihat dari sikap Hanah yang patuh pada ucapan suaminya dan hanya bisa membayangkan apa yang diinginkannya tanpa berani mengatakan pada suaminya. Sifat pasif jelas terlihat pada diri Hanah yang tak berani mengungkapkan apa yang dia inginkan dan apa yang seharusnya dia dapatkan sebagai seorang istri. Karena sikap tersebut kehidupan yang dia jalani tidak sesuai dengan apa yang diinginkannya.

\section{b. Sikap Pasrah}

Kehidupan yang ia bayangkan setelah menikah ternyata jauh dari kenyataanya. Hanah harus sabar jika semua keinginan tersebut menjadi nyata, yaitu Hanah harus melahirkan seorang anak yang selama ini didambakan suaminya. Pada cerpen "Telapak Kaki Yang Menyimpan Surga" tokoh Hanah juga mengalami ketidak adilan gender dan penindasan terhadap martabat wanita. Terbukti dari kutipan cerpen berikut.

"Saya telah menemukan seorang perempuan yang dapat membantumu menjadi seorang ibu?"

Air mataku mengering di sudut.

"Perempuan itu akan kunikahi segera. Agar sesegera mungkin, kau menjadi seorang ibu dengan telapak kaki yang menyimpan surga." Senyumnya lembut. 
Cairan-cairan di tubuhku bergerak ke arah yang berlawanan dan saling bertabrakan satu sama lain.

"Kamu tidak keberatan, kan?"

Aku menggeleng sambil membentuk garis senyuman.Kembang api berloncatan dari matanya. Warnanya serbacerah. (Telapak Kaki yang Menyimpan Surga karya Ni Komang Ariani pada koran Jawa Pos Edisi 18 September 2016).

Berdasarkan kutipan tersebut menggambarkan kontrafeminis pada sosok Hanah, sikap Hanah yang hanya bisa pasrah, dan menyetujui keinginan suaminya untuk berpoligami. Sikap Hanah juga terkesan bergantung pada suaminya, tidak bisa mandiri dan tidak mau mempertahankan rumah tangga yang selama ini ia impikan. Pada kutipan "Kamu tidak keberatan, kan?"Aku menggeleng sambil membentuk garis senyuman. Kembang api berloncatan dari matanya. Warnanya serbacerah.” Terlihat keterpaksaan seorang Hanah yang harus menelan pil pahit dari suami yang dicintai dan sangat dihormatinya. Merelakan harga dirinya untuk dimadu oleh suaminya yang hanya menginginkan adannya seorang anak yang tak kunjung hadir dalam rahimnya.

\section{c. Sikap Tidak Mandiri}

Tokoh Hanah yang menggantungkan dirinya pada sosok suami membuatnya menjadi wanita yang tidak memiliki hak atas dirinya sendiri, ia hanya menghamba pada suaminya. Hal tersebut membuat dirinya menjadi wanita yang tidak mandiri.

Seperti pada kutipan cerpen berikut.

"Ya sudah. Minggu depan saya akan ambil uang tabungan. Untuk membelikanmu bajubaju baru. Agar kau menjadi perempuan yang indah dan bisa memasuki pintu surga."

“Terima kasih, Mas. Tanpamu apakah saya ini.” (Telapak Kaki yang Menyimpan Surga karya Ni Komang Ariani pada koran Jawa Pos Edisi 18 September 2016).

Kutipan tersebut menggambarkan kontrafeminis pada tokoh Hanah karena ia menjadikan dirinya tidak berdaya dihadapan suaminya, Hanah tidak mau memperjuangkan martabatnya sebagai seorang istri. Sepert pada kutipan “Terima kasih, Mas. Tanpamu apakah saya ini." Jelas terlihat bahawa Hanah sangatlah bergantung pada suaminya dan tidak mau mandiri. Dalam kutipan diatas memperlihatkan pemikiran seorang Hanah bahwa wanita setelah menikah hanya akan melayani suami dan mendengarkan serta melakukan apapun yang diinginkan suami. Padahal meskipun sudah menikah seorang wanita pastinya masih memiliki hak untuk mandiri dan disegani, tapi harus didiskusikan dengan suami tentunya. 


\section{PENUTUP}

Dalam cerpen Telapak Kaki Yang Menyimpan Surga karya Ni Komang Ariani pada koran Jawa Pos edisi 18 September 2016, dikelompokkan atas tokoh profeminis dan kontrafeminis. Tokoh Hanah dengan profeminisnya yang mendukung ide feminis dan mempunyai keinginan untuk maju dan mandiri dengan cara ia sekolah dan beraktifitas diluar rumah. Sedangkan kontrafeminis dalam diri Hanah yaitu ia tetap tunduk patuh pada apapun yang diucapkan suaminya, ia terkesan bergantung pada suaminya tidak ingin mandiri, bahkan ia seperti menghamba pada suaminya. Pada penelitian ini tokoh Hanah lebih banyak terdapat kontrafeminis daripada profeminis, dikarenakan tokoh Hanah yang ingin menjadi istri sempurna untuk suaminya serta rumah tangganya.

\section{DAFTAR PUSTAKA}

Adji, Muhamad. (2009). Konstruksi Relasi Laki-laki dan Perempuan dalam Sistem Patriarki

(Kajian terhadap Karya Djenar Maesa Ayu dengan Pendekatan Feminisme). Bandung: Universitas Padjajaran.

Apriliya, Wulan. (2016). Citra Perempuan Dalam Novel Surga Yang Tak Dirindukan Karya Asma Nadia Dan Kaitannya Dengan Pembelajaran Sastra di SMA. Jurnal Ilmiah Widya Pustaka. Mataram NTB : FKIP Universitas Mataram.

Ariani, Ni Komang. (2016). Telapak Kaki Yang Menyimpan Surga. Semarang: Jawa Pos. Asmalasari, Devyanti. (2013). Eksistensi Perempuan Tionghoa dalam Novel Samita:Bintang

Berpijar di Langit Majapahit Karya Tasaro. Jurnal Metasastra. Bandung: Balai Bahasa Provinsi Jawa Barat.

Danial, Ahmad Ilham. (2012). Gambaran Feminisme Dalam Cerpen 'Ariadne' dan '.Gafya' Karya Anton Pavlovich Chekhov.Bandung: Universitas Padjajaran.

Djajanegara, Soenarjati. (2000). Citra Wanita dalam Lima Novel Terbaik Sinclair Lewis dan Gerakan Wanita di Amerika. Jakarta: Fakultas Sastra Universitas Indonesia.

Gora, Radita. 2015. Representasi Feminisme dalam Karya Sastra (Kajian Semiotik Sosial Novel "Eks Parasit Lajang” Karya Ayu Utami). Jurnal Cakrawala. Jakarta : BSI Jakarta. Ismawati, Esti. (2013). Karakter Perempuan Jawa dalam Novel Indonesia Berwarna Lokal Jawa:Kajian Perspektif Gender dan Transformasi Budaya. Jurnal Metasastra. Bandung: Balai Bahasa Provinsi Jawa Barat.

Juliah. (2015). Kajian Feminisme Marxim Dalam Novel Assalamualaikum Beijing Karya Asma Nadia. Jurnal Umrah. Tanjung Pinang : Universitas Maritim Raja Ali Haji. Moleong. (2008). Metodologi Penelitian Kualitatif. Bandung: PT Remaja Rosdakarya. 
Nugraheni, Imas Anggita.( 2015). Tokoh Mursiati Dalam Novel Katresnan Karya Soeratman Sastradihardja. Skripsi. Semarang : Universitas Negeri Semarang.

Solichah, Siti Aminatul. (2015). Karakteristik Tokoh Utama Dalam Novel Supiyah Karya Kusaeri YS (Kajian Feminisme Marxim). Jurnal Widyaloka. Surabaya : IKIP Widyaloka.

Suharto, Sugihastuti. (2010). Kritik Sastra Feminis. Yogyakarta : Pustaka Pelajar.

Syahfitri, Meilisa. (2013). Tokoh Wanita Profeminis Dan Kontra Feminis Dalam Novel Firdaus Yang Hilang Karya Mirna W. Jurnal Pendidikan Bahasa dan Sastra Indonesia. Padang: Universitas Negeri Padang.

Uli, Indriyana. (2011). Citra Perempuan dalam Novel Ratu Kecantikan Harga Sebuah Martabat karya Langit Kresna Hariadi. Jurnal Pendidikan Bahasa dan Sastra Indonesia. Pontianak: FKIP Untan.

Qomariyah, U'um. (2013). Potret Investasi Perempuan Berbasis Kearifan Lokal: Studi Ecofeminism Novel Primadona Karya Ahmad Munif. Jurnal Seloka. Semarang: Universitas Negeri Semarang. 